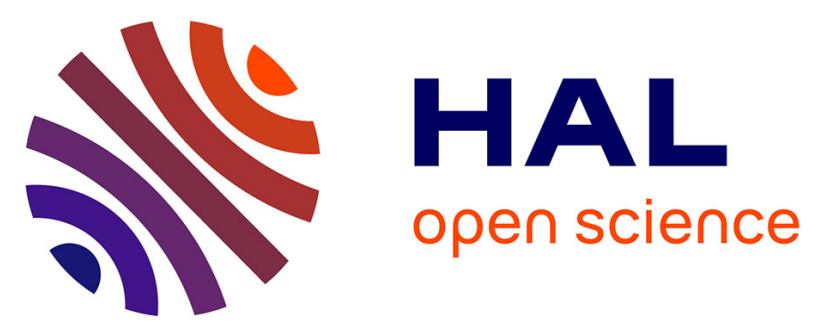

\title{
Enhanced Aging Model for Supercapacitors taking into account Power Cycling: Application to the Sizing of an Energy Storage System in a Direct Wave Energy Converte
}

Thibaut Kovaltchouk, Bernard Multon, Hamid Ben Ahmed, Judicael Aubry, Pascal Venet

\section{To cite this version:}

Thibaut Kovaltchouk, Bernard Multon, Hamid Ben Ahmed, Judicael Aubry, Pascal Venet. Enhanced Aging Model for Supercapacitors taking into account Power Cycling: Application to the Sizing of an Energy Storage System in a Direct Wave Energy Converte. EVER 2014, Mar 2014, Monaco, Monaco. pp 1-9, 10.1109/EVER.2014.6844039 . hal-01061016

\section{HAL Id: hal-01061016 https://hal.science/hal-01061016}

Submitted on 4 Sep 2014

HAL is a multi-disciplinary open access archive for the deposit and dissemination of scientific research documents, whether they are published or not. The documents may come from teaching and research institutions in France or abroad, or from public or private research centers.
L'archive ouverte pluridisciplinaire HAL, est destinée au dépôt et à la diffusion de documents scientifiques de niveau recherche, publiés ou non, émanant des établissements d'enseignement et de recherche français ou étrangers, des laboratoires publics ou privés. 


\section{Enhanced Aging Model for Supercapacitors taking into account Power Cycling: Application to the Sizing of an Energy Storage System in a Direct Wave Energy Converter}

\author{
Thibaut Kovaltchouk, Bernard Multon, \\ Hamid Ben Ahmed \\ SATIE, UMR CNRS 8029 \\ ENS Rennes, UEB \\ av. Robert Schuman \\ 35170 Bruz, France \\ thibaut.kovaltchouk@ens-rennes.fr
}

\author{
Judicaël Aubry \\ Équipe mécatronique, \\ Pascal Venet \\ AMPERE UMR CNRS 5005 \\ ESTACA, Campus de Laval Université Lyon 1, Université de Lyon \\ Rue Georges Charpak \\ 43 bd du 11 Novembre \\ 53061 Laval, France
}

\begin{abstract}
This paper proposes an original model for supercapacitors that takes into account both calendar aging and cycling aging. This model is based on a series of recent experiments conducted in various research laboratories on the same technology (Maxwell Technology) and serves to represent the degradation of Equivalent Series Resistance and capacitance. We show that an accurate aging model is critical to the design of an Energy Storage System that optimizes the economic life cycle cost. Such an optimization is especially applicable for smoothing in offshore systems like Direct Wave Energy Converters, which require both cost reduction and high reliability. The influence of an aging model in the sizing process is investigated towards the end of this paper.
\end{abstract}

Keywords-Supercapacitors; Aging; Energy Storage Systems; Direct Wave Energy Converter; Power Smoothing; Power Cycling; Irregular Waves.

\section{INTRODUCTION}

Supercapacitors, also known as Electric Double-Layer Capacitors, ultracapacitors or Electrochemical DoubleLayer Capacitors (EDLC), cannot compete with batteries

(C) 2014 IEEE. Personal use of this material is permitted. Permission from IEEE must be obtained for all other uses, including reprinting/republishing this material for advertising or promotional purposes, collecting new collected works for resale or redistribution to servers or lists, or reuse of any copyrighted component of this work in other works

Kovaltchouk, Thibaut; Multon, Bernard; Ben Ahmed, Hamid; Aubry, Judicael; Venet, Pascal, "Enhanced aging model for supercapacitors taking into account power cycling: Application to the sizing of an Energy Storage System in a Direct Wave Energy Converter," Ecological Vehicles and Renewable Energies (EVER), 2014 Ninth International Conference on , pp.1,10, 25-27 March 2014 DOI: 10.1109/EVER.2014.6844039 in terms of energy density, yet their much longer cycling life, power density and operating temperature range make them an energy storage option to be seriously considered in many applications, whether mobile [1] or stationary [2].

To ensure enduring performance over its lifetime, supercapacitor reliability must be quantified by means of accelerated aging tests and/or application of an aging model. Many laboratories and manufacturers have conducted calendar and cycling aging tests [3]-[10]. The present paper uses these tests in order to build an advanced aging model for supercapacitors. This model is then implemented to size an Energy Storage System (ESS) for a Direct Wave Energy Converter (DWEC) and compared to the application of conventional aging models.

Power fluctuation minimization is one of the keys for developing direct electricity production from fluctuating renewable energies, especially in the case of direct wave energy conversion, where the output power is strongly pulsating. The problem herein is to satisfy a power quality constraint, e.g. the flicker [11], so as to ensure grid integration thanks to supercapacitor energy storage systems.

In our case, the studied DWEC is the SEAREV [12][13] (see figure 1); it consists of a completely enclosed floating buoy with an embedded pendular wheel. Excitation forces from the swell on the buoy generate relative motion between the float and the wheel; this oscillating motion is then damped in order to produce energy. 


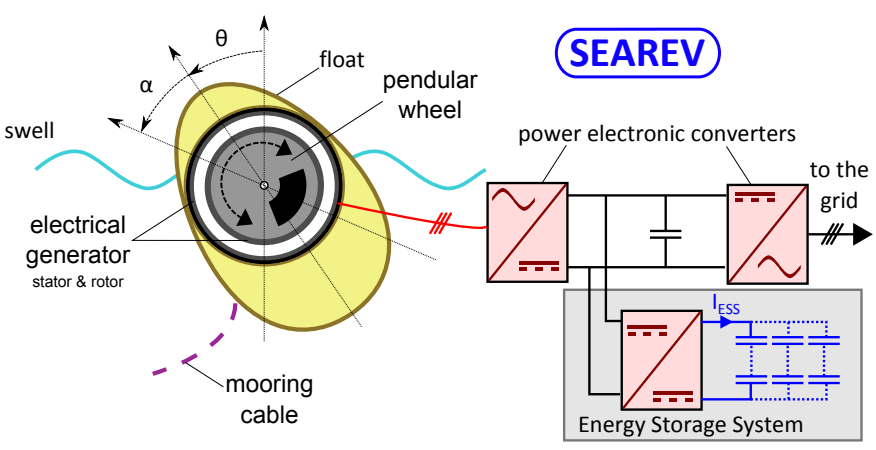

Fig. 1. Main diagram of the SEAREV Direct Wave Energy Converter with a Supercapacitor Power Smoothing System

Damping is ensured by a three-phase Permanent Magnet Synchronous Generator (PMSG) connected to a backto-back converter. The PMSG is a surface permanent magnet, low-speed high-torque machine with 124 pole pairs; its design has been optimized to minimize the per$\mathrm{kWh}$ production cost [13]. The back-to-back converter is composed of: a Pulse Width Modulation (PWM) inverter connected to the PMSG, for controlling damping; a PWM-inverter connected to the grid, for regulating the DC bus voltage and supplying the grid with power; and a chopper connected to the supercapacitors, for smoothing electrical power output (see figure 1).

\section{LIFETIME CALENDAR MODEL}

\section{A. Electrical model}

The electrical model chosen to represent a supercapacitor is the series connection of a capacitance $C$ and resistance ESR (Equivalent Series Resistance). The temperature dependence of these parameters has not been considered herein. More complex models exist, yet this simplified one is sufficient to compute losses with the level of precision required for a sizing process. Moreover, these electrical parameters are given in the manufacturer's datasheet.

\section{B. Classical Eyring's Law}

The classical aging model for supercapacitors is Eyring's Law, which yields the lifetime. For our purposes, the lifetime is considered when the capacity $C$ is reduced by $20 \%$ or the resistance $E S R$ is doubled. Calendar tests are performed to determine the parameters of this equation. Voltage and temperature remain constant over time in these tests.

$$
\begin{aligned}
T_{\text {life }}\left(V, \theta_{c}\right) & =T_{\text {life }}^{r e f} \cdot \exp \left(\ln (2) \frac{\theta_{c}^{r e f}-\theta_{c}}{\theta_{0}}\right) \\
& \times \exp \left(\ln (2) \frac{V^{r e f}-V}{V_{0}}\right)
\end{aligned}
$$

where $T_{\text {life }}$ is the lifetime in hours, $\theta_{c}$ the case temperature, and $V$ the voltage across the component. $\theta_{0}$ and $V_{0}$ are the respective decreases in temperature and voltage necessary to double the lifetime. $T_{\text {life }}^{r e f}$ is the lifetime, in hours, for a case temperature of $\theta_{c}^{\text {ref }}$ (here, the maximum operating temperature, $65^{\circ} \mathrm{C}$ ) with a voltage of $V^{\text {ref }}$ (here, the rated voltage, $2.7 \mathrm{~V}$ ).

We deduce from (1) a dynamical aging model which leads to the same result. The hypothesis introduced at this time is that degradation speed is solely dependent on $V$ and $\theta_{c}$. With Equation (1), we have defined a variable State-of-Aging $S o A$ to represent the aging over time. The value is 0 initially and reaches 1 at the end of the lifetime:

$$
\frac{\mathrm{d} S o A}{\mathrm{~d} t}\left(V, \theta_{c}\right)=\frac{1}{T_{l i f e}\left(V, \theta_{c}\right)}
$$

In this paper, we will consider the Maxwell technology. Several laboratories have conducted calendar tests and deduced the corresponding parameters [3]-[8]. Some results are shown in Table I.

TABLE I. COMPARISONS OF LIFETIME EXPECTANCY ACCORDING TO MANUFACTURER AND LABORATORY MODELS FOR MAXWELL TECHNOLOGY (350 F, 2600 F OR 3000 F)

\begin{tabular}{|c|c|c|c|}
\hline & $\theta_{0}$ & $V_{0}$ & $T_{\text {life }}^{\text {ref }}$ \\
\hline Maxwell datasheets [3] & - & - & $1500 \mathrm{~h}$ \\
\hline LUSAC [4] & $8.7 \mathrm{~K}$ & - & $1550 \mathrm{~h}$ \\
\hline IMS [5] & - & $100 \mathrm{mV}$ & $1910 \mathrm{~h}$ \\
\hline RWTH [6] & $10 \mathrm{~K}$ & $100 \mathrm{mV}$ & $1500 \mathrm{~h}$ \\
\hline PSI [7] & $10 \mathrm{~K}$ & $95 \mathrm{mV}$ & $1450 \mathrm{~h}$ \\
\hline Ampère [8] & $8.6 \mathrm{~K}$ & $87 \mathrm{mV}$ & $1500 \mathrm{~h}$ \\
\hline
\end{tabular}

\begin{tabular}{|c|c|c|}
\hline & $T_{\text {life }}\left(2.7 \mathrm{~V}, 25^{\circ} \mathrm{C}\right)$ & $T_{\text {life }}\left(0 \mathrm{~V}, 70{ }^{\circ} \mathrm{C}\right)$ \\
\hline Maxwell datasheets [3] & 10 years & 4 years \\
\hline LUSAC [4] & 4.3 years* & - \\
\hline IMS [5] & - & - \\
\hline RWTH [6] & 2.7 years* & $16 \times 10^{6}$ years* \\
\hline PSI [7] & 2.6 years* & $42 \times 10^{6}$ years* \\
\hline Ampère [8] & 4.4 years* & $260 \times 10^{6}$ years* \\
\hline \multicolumn{2}{|c|}{ "These values correspond to extrapolations. }
\end{tabular}

\section{Accounting for high-temperature, low-voltage aging}

We notice that there is a huge difference between models extrapolations and datasheet value in the last column of table I which represent a low-voltage hightemperature case. The model presented in (2) cannot explain aging when the supercapacitor is fully discharged 
and the storage temperature is high. So we modify the equation in order to model this phenomenon.

$$
\begin{aligned}
\frac{\mathrm{d} S o A}{\mathrm{~d} t} & =\frac{1}{T_{\text {life }}^{r e f}} \cdot \exp \left(\ln (2) \frac{\theta_{c}-\theta_{c}^{r e f}}{\theta_{0}}\right) \\
& \times\left[\exp \left(\ln (2) \frac{V-V^{r e f}}{V_{0}}\right)+K\right]
\end{aligned}
$$

where $K$ is a dimensionless constant that replaces the voltage term whenever voltage is low. This adjustment is arbitrary and must be considered with caution: others low-voltage experiments are necessary to confirm or rebut this model.

A total of 23 calendar experiments from [3]-[9] have been examined for the purpose of optimizing the four parameters $\left(T_{\text {life }}^{r e f}, \theta_{0}, V_{0}\right.$ and $\left.K\right)$. Regression is applied on $\log \left(T_{l i f e}\right)$. Results are shown in Table II. The comparison between model and experimental outputs is presented in figure 2. The coefficient of determination $\left(R^{2}\right)$ is equal to $96 \%$ (on a logarithmic scale), which means that $96 \%$ of the variations in lifetime for these 23 tests can be explained by our model.

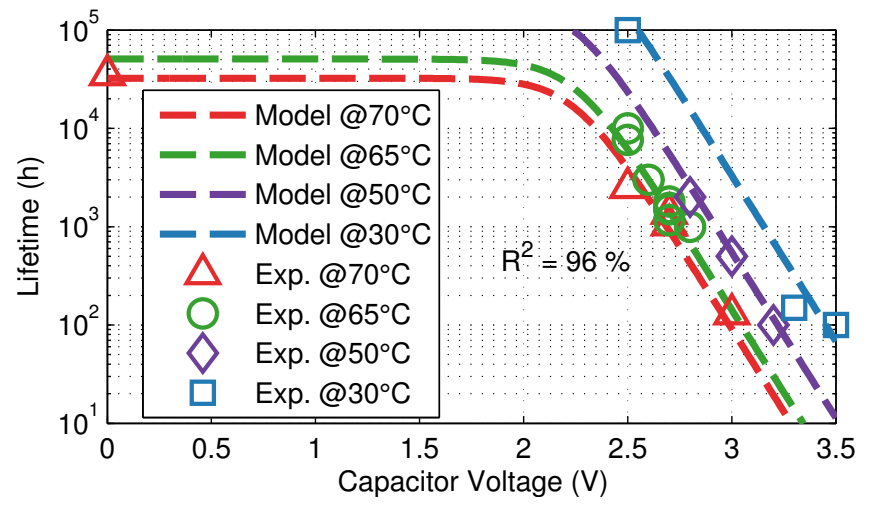

Fig. 2. Calendar lifetime as a function of voltage for four case temperatures $\left(70^{\circ} \mathrm{C}, 65^{\circ} \mathrm{C}, 50^{\circ} \mathrm{C}\right.$ and $\left.30^{\circ} \mathrm{C}\right)$ : Comparison between the model and experiments from [3]-[9]

TABLE II. PARAMETERS FOR THE CALENDAR AGING MODEL AND LIFETIME EXPECTANCY

\begin{tabular}{|c|c|}
\hline$\theta_{0}$ & $7.7 \mathrm{~K}$ \\
\hline$V_{0}$ & $89 \mathrm{mV}$ \\
\hline$K$ & $29.10^{-3}$ \\
\hline$T_{\text {life }}^{r e f}$ & $1470 \mathrm{~h}$ \\
\hline$V^{\text {ref }}$ & $2.7 \mathrm{~V}$ \\
\hline$\theta_{c}^{\text {ref }}$ & $65^{\circ} \mathrm{C}$ \\
\hline$T_{\text {life }}\left(2.7 \mathrm{~V}, 25^{\circ} \mathrm{C}\right)$ & 5.9 years \\
\hline$T_{\text {life }}\left(0 \mathrm{~V}, 70^{\circ} \mathrm{C}\right)$ & 3.7 years \\
\hline
\end{tabular}

\section{INCORPORATING POWER CYCLING INTO THE MODEL}

Given the small number of fully-documented cycling aging tests in the literature and aging mechanisms that differ somewhat from one manufacturer to the next, the experiments used to build this model have been conducted with similar supercapacitor cells $(2600 \mathrm{~F}$ and $3000 \mathrm{~F}$ from Maxwell Technologies). The 8 experiments referred to in this paper have all been conducted in two French laboratories: Ampère Laboratory [8][9] and IMS Laboratory [5][14].

\section{A. Degradation of electrical parameters as a function of aging}

The two electrical parameters $C$ and ESR change with age. Two distinct phases are observed: an initial burning phase, and a linear phase [15]. We propose herein to model just the linear phase with the capacitance and conductance (i.e. the inverse of $E S R$ ) parameters, which decrease linearly with the State-of-Aging variable $S o A$ (in proportion with time at constant voltage and temperature). Similar hypotheses have been previously adopted in [6][13].

$$
\begin{aligned}
C & =C_{0}(0.95-0.15 \text { SoA }) \\
E S R^{-1} & =E S R_{0}^{-1}(1-0.3 \text { SoA })
\end{aligned}
$$

where $C_{0}$ and $E S R_{0}$ are respectively the initial values of $C$ and $E S R$.

Four experiments were used to derive this law. The level of agreement between experiment and model is shown in figure 3 . The quick burning phase at the time of startup is not taken into account, hence the capacity changes instantaneously from $100 \%$ to $95 \%$ at $S o A=0$. The ratio between the speeds with which relative resistance and relative capacitance decrease is equal to 2 for our model. This ratio lies between 1.5 and 2 in [6] and equals 2.5 in [13].

\section{B. Thermal model}

The self-heating effect is very important because the degradation rate accelerates exponentially with respect to temperature. The thermal time constant of the cell (around $1900 \mathrm{~s}$ for the BCAP3000 cell) is considered herein to be high enough relative to the time cycle (typically a few tens of seconds) so as to neglect case temperature variations. In order to determine the case temperature of the elements, we thus introduce a simple static thermal model:

$$
\theta_{c}=\theta_{a}+R_{\text {thca }}<E S R \cdot I(t)^{2}>
$$




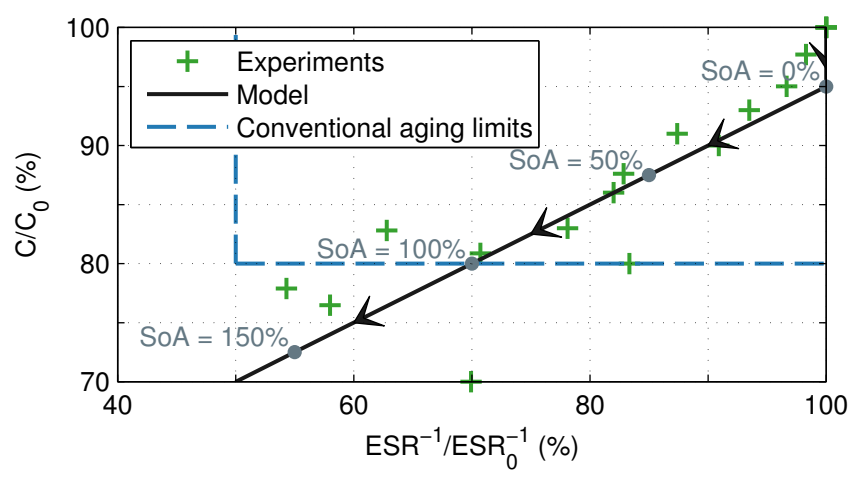

Fig. 3. Evolution of electrical parameters input into the electrical model in the (Relative conductance - Relative capacitance) plane: Comparison between model and experiments [5][8][9][14].

where $\theta_{a}$ is the ambient temperature, $R_{t h c a}$ the thermal resistance of the element, and $I$ the current flowing through the component.

\section{Calendar aging model applied to cycling tests}

With the above calendar model (equations (3), (4), (5) and (6)), aging during the cycling test can be simulated.

During cycling tests, the waveforms of current $I(t)$ and voltage $V(t)$ depend on aging due to their dependence on electrical parameters $C$ and $E S R$. Consequently, the RMS (Root Mean Square) current, losses and self-heating all depend on the State-of-Aging.

To predict a lifetime, it is necessary to compute cycling with different States-of-Aging. The method used in this paper is a simple adaptive step-size resolution with an aging resolution of $\triangle S o A=1 \%$; it is illustrated in figure 4 .

\section{Aging dependence in an RMS current}

Let's begin by comparing these simulations with the results obtained from the 8 experiments. It should be noted that the recovery during stoppage has not been considered, as recommended by the manufacturer [16].

The residuals are too important to consider that the model used is sufficient: the results from the cycling tests are between 20 and 200 smaller than lifetime from simulations (see figure 5). Let's define an accelerator factor $k_{a c c}^{(i)}$ for each experiment $i$ that represents the acceleration due to the cycling test as compared to an equivalent calendar aging. This accelerator is defined by:

$$
k_{\text {acc }}^{(i)}=\frac{\tilde{T}_{\text {life }}^{(i)}}{T_{\text {life }}^{(i)}}
$$

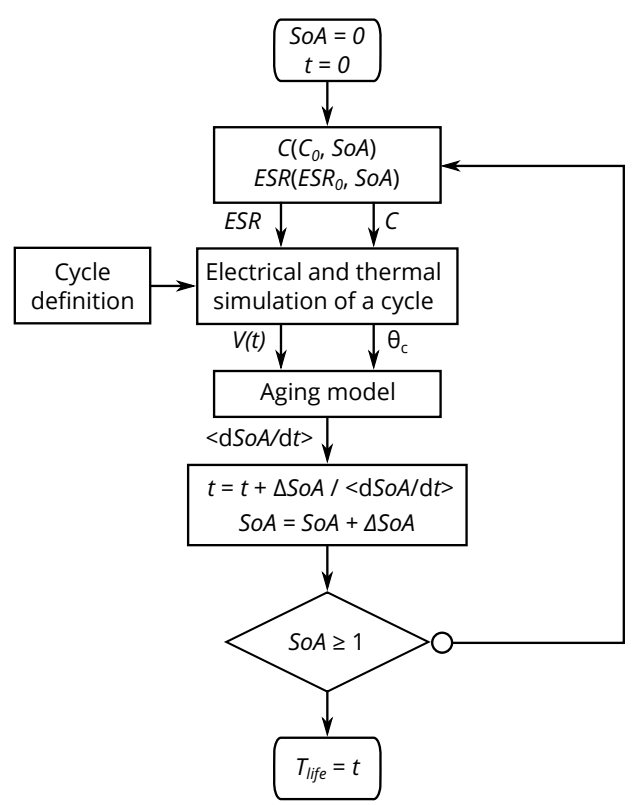

Fig. 4. Method for computing lifetime $T_{\text {life }}$ with the evolution in capacitance $C$ and $E S R$ : A simple adaptive step-size method (with $\triangle S o A=1 \%$ )

where $\tilde{T}_{\text {life }}^{(i)}$ is the theoretical result obtained with the calendar aging model, and $T_{\text {life }}^{(i)}$ is the result for experiment $i$.

Figure 5 shows the 8 values for $k_{a c c}^{(i)}$ as a function of the relative RMS current $\left(I_{R M S} / C_{0}\right)$ : Clearly, $k_{a c c}^{(i)}$ is dependent on this value. The RMS current dependency has already been investigated in [9].

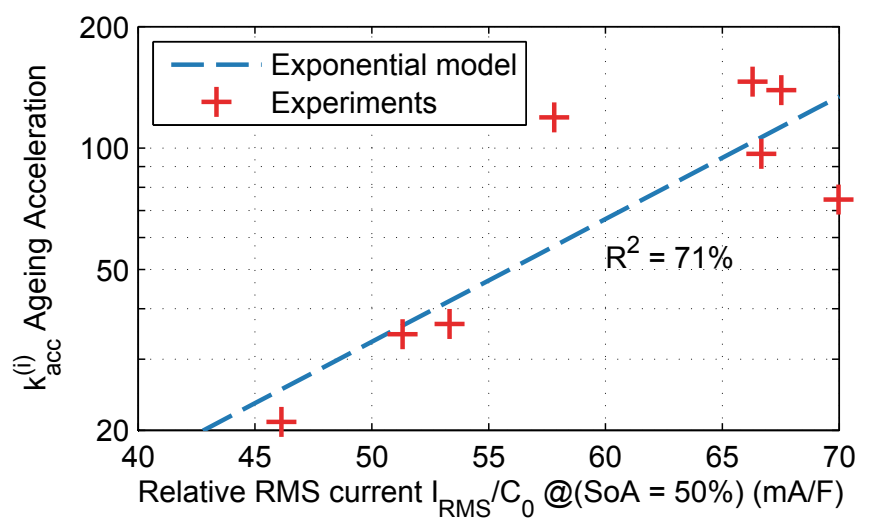

Fig. 5. Acceleration of aging vs. calendar model results as a function of relative RMS current across the component at a $50 \%$ State-ofAging

An enhanced model is thus being proposed here, as 
inspired by [9]:

$$
\begin{aligned}
\frac{\mathrm{d} S o A}{\mathrm{~d} t} & =\frac{1}{T_{\text {life }}^{\text {ref }}} \cdot \exp \left(\ln (2) \frac{\theta_{c}-\theta_{c}^{\text {ref }}}{\theta_{0}}\right) \\
& \times\left[\exp \left(\ln (2) \frac{V-V^{r e f}}{V_{0}}\right)+K\right] \\
& \times \exp \left(k_{R M S} \frac{\tilde{I}_{R M S}}{C_{0}}\right)
\end{aligned}
$$

where $\tilde{I}_{R M S}$ is an approximation of the RMS current flowing through the component.

The computation of $\tilde{I}_{R M S}$ involves a three-step procedure:

1) Compute the square current (9),

2) Then, filter it with a first-order low-pass filter and time constant $\tau_{\text {filter }}(10)$,

3) Finally, take the root square of the result (11).

$$
\begin{aligned}
x(t) & =I(t)^{2} \\
Y(s) & =\frac{X(s)}{1+\tau_{\text {filter }} s} \\
\tilde{I}_{R M S}(t) & =\sqrt{y(t)}
\end{aligned}
$$

where $X(s)$ and $Y(s)$ are respectively the Laplace transform of $x(t)$ and $y(t)$, two intermediate variables expressed in a unit of $\mathrm{A}^{2}$.

The two additional parameters $k_{r m s}$ and $\tau_{\text {filter }}$ are optimized to fit the experimental data. All these model parameters are listed in Table III. The comparison between data recorded and model output is shown in figure 6 .

The coefficient of determination (71\%) is less than that for the calendar model, which gives rise to several explanations:

- Model imperfection (including the choice of $\tilde{I}_{R M S}$ as an explanatory parameter)

- A precise knowledge of experimental parameters: ambient temperature, cycle definition, evolution in electrical parameters during testing

- Component variability.

\section{Sizing of an Energy Storage System}

A sea-state is described by its significant wave height $H_{s}$ and peak wave period $T_{p}$; this state provides important information on the power source, such as wind speed for wind turbines. Let's consider herein a unique
TABLE III.

PARAMETERS INPUT INTO THE CYCLING AGING MODEL

\begin{tabular}{|c|c|}
\hline$\theta_{0}$ & $7.7 \mathrm{~K}$ \\
\hline$V_{0}$ & $89 \mathrm{mV}$ \\
\hline$K$ & $29.10^{-3}$ \\
\hline$T_{\text {life }}^{\text {ref }}$ & $1470 \mathrm{~h}$ \\
\hline$V^{\text {ref }}$ & $2.7 \mathrm{~V}$ \\
\hline$\theta^{\text {ref }}$ & $65^{\circ} \mathrm{C}$ \\
\hline$k_{R M S}$ & $68 \mathrm{~s} . \mathrm{V}^{-1}$ \\
\hline$\tau_{\text {filter }}$ & $45 \mathrm{~s}$ \\
\hline
\end{tabular}

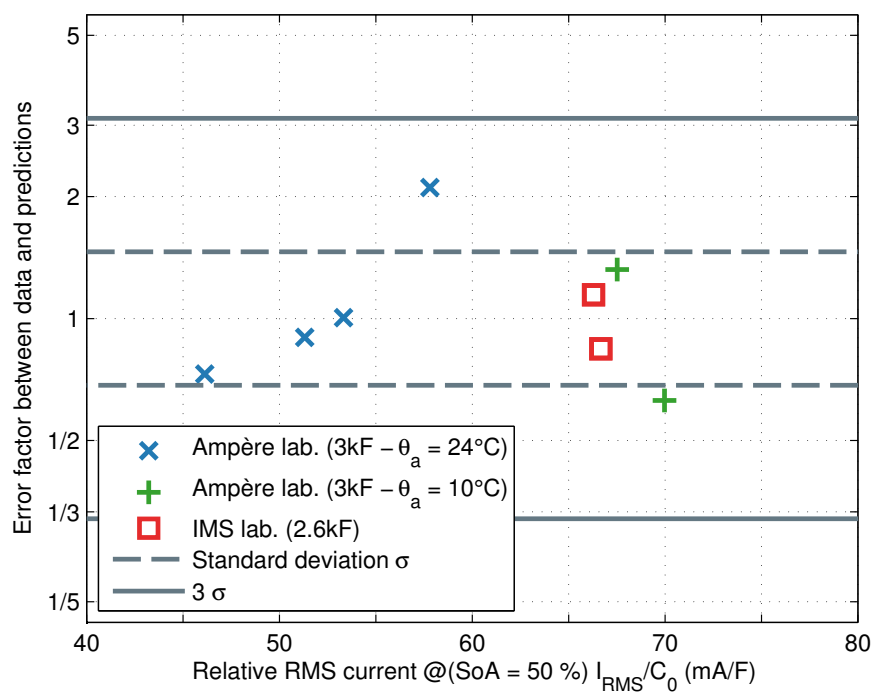

Fig. 6. Ratio between lifetime derived by the tests and cycling model predictions as a function of relative RMS current across the supercapacitor at a $50 \%$ State-of-Aging

sea-state, adopted as the design sea-state: $H_{s}=2.5 \mathrm{~m}$ and $T_{p}=8 \mathrm{~s}$. The energy produced with this sea-state (average power: $190 \mathrm{~kW}$ ) over 13 years corresponds to the energy produced by the system over 20 years at the Yeu Island site (France).

\section{A. Electrical Model of the Energy Storage System}

The Energy Storage System (ESS), as described in figure 1, will be composed of $N_{\text {Cells }}$ Maxwell BCAP3000 reference cells $\left(C_{0}=3000 \mathrm{~F}, V_{\text {Rated }}=2.7 \mathrm{~V}\right.$ and $E S R_{0}=0.29 \mathrm{~m} \Omega$ ). The series and parallel connections of these elements allow adjusting the rated voltage and total size of the ESS. This model is the same whether for the entire system or an individual element, i.e.: a capacity $C_{E S S}$ in series with an equivalent series resistance $E S R_{E S S}$. All cells are assumed to be identical. The voltage at the capacity terminal is denoted $V_{E S S}$ (capacitive voltage), while the current flowing through the system is denoted $I_{E S S}$.

The energy stored in the ESS $E_{S t o}$, the rated system energy $E_{\text {Rated }}$ and system losses $P_{\text {Loss }}$ are then all easy 
to compute for each time step:

$$
\begin{aligned}
E_{\text {Sto }} & =\frac{1}{2} \cdot C_{E S S} \cdot V_{E S S}^{2} \\
& =N_{\text {Cells }} \cdot \frac{1}{2} \cdot C \cdot V^{2} \\
E_{\text {Rated }} & =\frac{1}{2} \cdot C_{E S S 0} \cdot V_{E S S \text { Rated }}^{2} \\
& =N_{\text {Cells }} \cdot \frac{1}{2} \cdot C_{0} \cdot V_{\text {Rated }}^{2} \\
P_{\text {Loss }} & =C_{E S S} \cdot E S R_{E S S} \cdot \frac{P_{\text {Sto }}^{2}}{2 E_{\text {Sto }}} \\
& =C \cdot E S R \cdot \frac{P_{\text {Sto }}^{2}}{2 E_{\text {Sto }}}
\end{aligned}
$$

where $P_{\text {Sto }}$ is the power in the ESS.

\section{B. Objective and power control of the Energy Storage System}

The Energy Storage System is necessary to satisfy the flicker constraint. The long-term flicker severity $P_{l t}$ for a wave farm is 0.25 , according to French rules for an HTA Grid (distribution grid between $1 \mathrm{kV}$ and $50 \mathrm{kV}$, typically $20 \mathrm{kV})$.

We are assuming herein that the flicker severity for a Wave Energy Converter farm can be computed under the same hypothesis as for the wind turbine farm in [17]. The total long-term flicker severity $P_{l t}$ for a farm with $N_{i}$ converters and the same individual long-term severity $P_{l t i}$ is assumed to equal: $P_{l t}=\sqrt{N_{i}} \cdot P_{l t i}$.

Let's now assume a situation with 10 productive units; then, the limit for each unit would be: $0.25 / \sqrt{10}=$ 0.079. This constraint will be used to size the individual Energy Storage System (ESS), which is controlled individually.

Let's also assume that the grid has a short-circuit apparent power of $50 \mathrm{MVA}$ and a grid impedance angle of $60^{\circ}$, both of which are typical values for a weak medium-voltage grid. In order to limit grid current, the grid reactive power production is set to: $Q_{\text {Grid }}=0$.

The energy policy requires information on the energy in the ESS; it is considered that this energy can be deduced from the value of capacitive voltage $V_{E S S}$, with no information on the $S o A$ or value of $C_{E S S}$ :

$$
\tilde{E}_{S t o}=\frac{1}{2} \cdot 0.8 \cdot C_{E S S 0} \cdot V_{E S S}^{2}
$$

where $\tilde{E}_{S t o}$ is the estimated energy in the storage system when considering the capacitive voltage. It is important to note that this value is always underestimated whenever $S o A<1$.

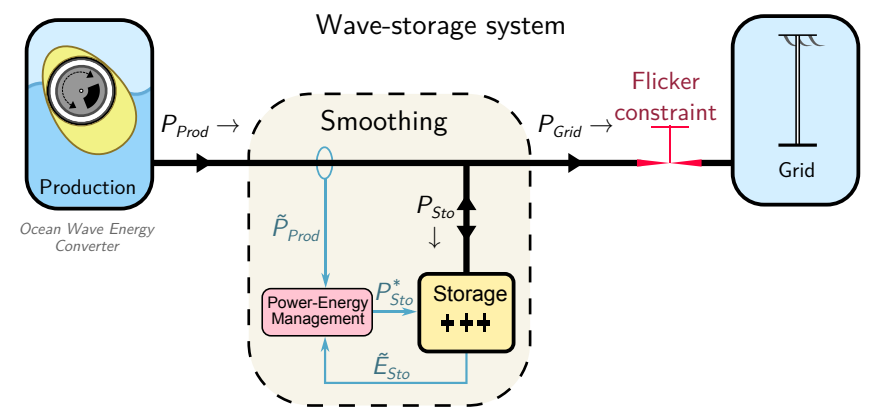

Fig. 7. Power smoothing with Energy Storage to satisfy a flicker constraint

The production power $P_{\text {Prod }}$ is filtered using the Energy Storage System via a very simple control strategy: grid power $P_{\text {Grid }}$ has a linear relationship with the estimated energy contained in the ESS:

$$
\begin{aligned}
P_{\text {Grid }} & =\frac{\tilde{E}_{\text {Sto }}-\tilde{E}_{M i n}}{\tau_{\text {Sto }}} \\
P_{\text {Grid }} & =\frac{0.8 \cdot C_{E S S 0}}{C_{E S S}} \frac{E_{S t o}-E_{M i n}}{\tau_{S t o}}
\end{aligned}
$$

where $\tilde{E}_{M i n}$ is the minimum estimated energy in the ESS, $E_{M i n}$ the minimum energy in the ESS, and $\tau_{S t o}$ a time constant used to define the energy policy.

Storage power $P_{S t o}$ can therefore be expressed as:

$$
\begin{aligned}
\frac{\mathrm{d} E_{S t o}}{\mathrm{~d} t} & =P_{S t o} \\
& =P_{\text {Prod }}-\frac{0.8 \cdot C_{E S S 0}}{C_{E S S}} \frac{E_{S t o}-E_{M i n}}{\tau_{S t o}}
\end{aligned}
$$

These equations are illustrated in figure 7.

This control strategy ensures energy limitations whenever power production $P_{\text {Prod }}$ is bounded, and such is the case here with $0 \leq P_{\text {Prod }} \leq P_{\text {Max }}=1.1 \mathrm{MW}$. These limitations are:

$$
\begin{aligned}
E_{\text {Min }} & =\frac{C_{E S S}}{0.8 \cdot C_{E S S 0}} \tilde{E}_{\text {Min }} \\
& =\frac{1}{2} \cdot C_{E S S} \cdot V_{E S S M i n}^{2} \\
E_{\text {Max }} & =E_{\text {Min }}+\frac{C_{E S S}}{0.8 \cdot C_{E S S 0}} \cdot \tau_{S t o} \cdot P_{\text {Max }} \\
& =\frac{1}{2} \cdot C_{E S S} \cdot\left(V_{E S S M i n}^{2}+\frac{2 \cdot \tau_{S t o} \cdot P_{M a x}}{0.8 \cdot C_{E S S 0}}\right) \\
& =\frac{1}{2} \cdot C_{E S S} \cdot V_{E S S M a x}^{2}
\end{aligned}
$$

where $E_{M i n}$ and $E_{M a x}$ are the boundaries for energy (proportional to $C_{E S S}$, hence dependent on $S o A$ ), and $V_{E S S M i n}$ and $V_{E S S M a x}$ the boundaries for capacity 
voltage (independent of $C_{E S S}$ and therefore of $S o A$ ). To limit aging, the maximum voltage allowed is limited: $V_{\text {Max }}=2.5 \mathrm{~V}$.

The Laplace transformation of Equation (18) yields a relationship between power production and grid power as follows:

$$
\begin{gathered}
\frac{P_{\text {Grid }}(s)}{P_{\text {Prod }}(s)}=\frac{1}{1+\frac{C_{E S S}}{0.8 \cdot C_{E S S 0}} \cdot \tau_{\text {Sto }} \cdot s} \\
=\frac{1}{1+\tau_{\text {Sto }}^{\prime} \cdot s}
\end{gathered}
$$

where $P_{\text {Grid }}(s)$ and $P_{\text {Prod }}(s)$ are respectively the Laplace transform of $P_{G r i d}(t)$ and $P_{\text {Prod }}(t)$, and $\tau_{\text {Sto }}^{\prime}=$ $\left(C_{E S S}\right) /\left(0.8 \cdot C_{E S S O}\right) \cdot \tau_{S t o}$ is the time constant of the equivalent filter. Production is then smoothed by a firstorder low-pass filter.

As could have been predicted, the filter functions better with a new ESS (filter constant time $=\tau_{\text {Sto }} / 0.8$ ) rather than with an older ESS (at the end of ESS life, filter constant time $=\tau_{S t o}$ ). The variable $\tau_{S t o}$ is chosen to satisfy the constraint limit in the worst case.

Figure 8 shows, for the same production, the effect of aging on both the grid power and voltage. Let's remark that the difference between grid power in both cases is small. Each time simulation lasts 30 minutes and is repeated 100 times in order to compute the lifetime, as explained in figure 4 and shown in figure 9.

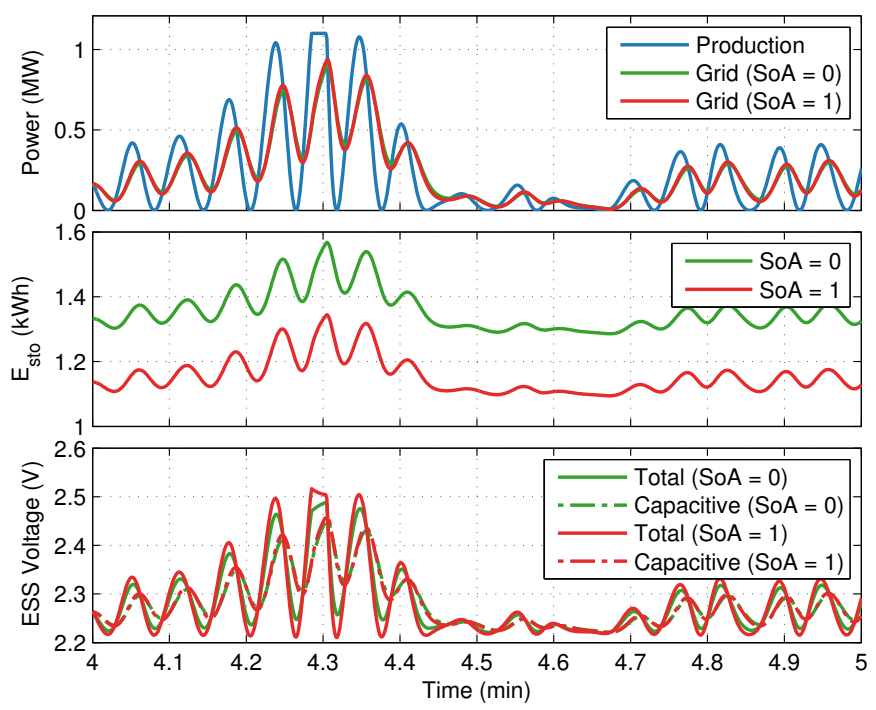

Fig. 8. Power production, grid power, stored energy and ESS voltage vs. time with the two extreme aging values for an energy rating of $2 \mathrm{kWh}$ - Extracted from a 30-minute simulation

The risk of thermal runaway is present at the end of the lifetime due to the fact that self-heating is proportional to $E S R$ and therefore its increase tends to accelerate. Figure 9 shows aging $S o A$, the evolution in losses and degradation speed vs. time. Let's point out that the acceleration in aging near the end of the lifetime is not very significant. A good approximation for computing losses and degradation speed seems to calculate these values at system midlife $(S o A=0.5)$.

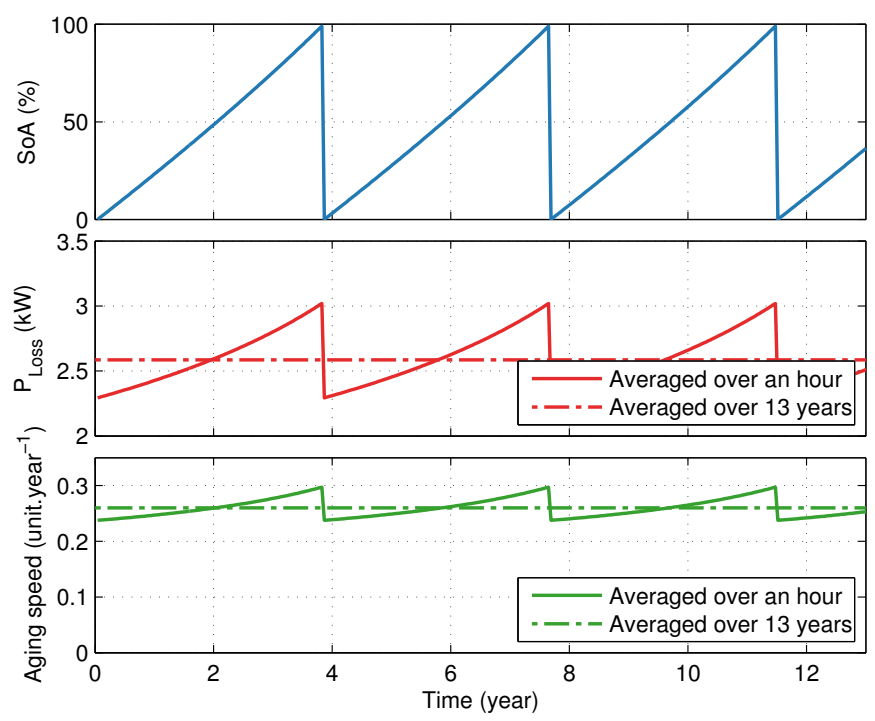

Fig. 9. State of Aging: average loss of power and degradation speed vs. time for an energy rating of $2 \mathrm{kWh}$ (with 3 replacements during the 13 years)

\section{Life cycle model}

The goal of this model is to determine the sizing that minimizes total lifetime cost; this cost takes into account the price of losses using a feed-in tariff set at $0.15 € / \mathrm{kWh}$, with the initial investment costing $20 \mathrm{k} € / \mathrm{kWh}$ (corresponding to approximately $20 € / \mathrm{kF}$ according to this technology) and a proportional replacement cost that considers the price of the new storage system.

$$
\begin{aligned}
& C_{\text {life }}(\mathrm{k} €)=20 \cdot\left(1+N_{\text {replace }}\right) \cdot E_{\text {Rated }}(\mathrm{kWh}) \\
& \quad+0.1510^{-3} \cdot P_{\text {loss }}(\mathrm{kW}) \cdot 8766(\mathrm{~h}) \cdot 13(\text { years })
\end{aligned}
$$

where $N_{\text {replace }}$ is the number of replacements and has been assumed here as a continuous variable to improve the precision of results. In reality, this number is obviously an integer.

This model does not take into account either the intervention cost or production losses during failure, both of which can be considerable in an offshore system.

For each energy rating, the evolution in losses and degradation is computed as described in the previous section, thus yielding a computation of the life cycle cost. Results are shown in figure 10. The red zone 
corresponds to insufficient energy with respect to the flicker constraint, while the dark green zone indicates the initial investment, the light green zone the replacement cost, and the yellow zone the ESS losses. The first figure corresponds to no use of an aging model, while the second figure displays a conventional aging model (without current) as well as the enhanced model proposed herein. Let's focus on two specific energy rating values: the economic optimum with the conventional model (marked with a circle) and then with the enhanced model (marked with a cross).

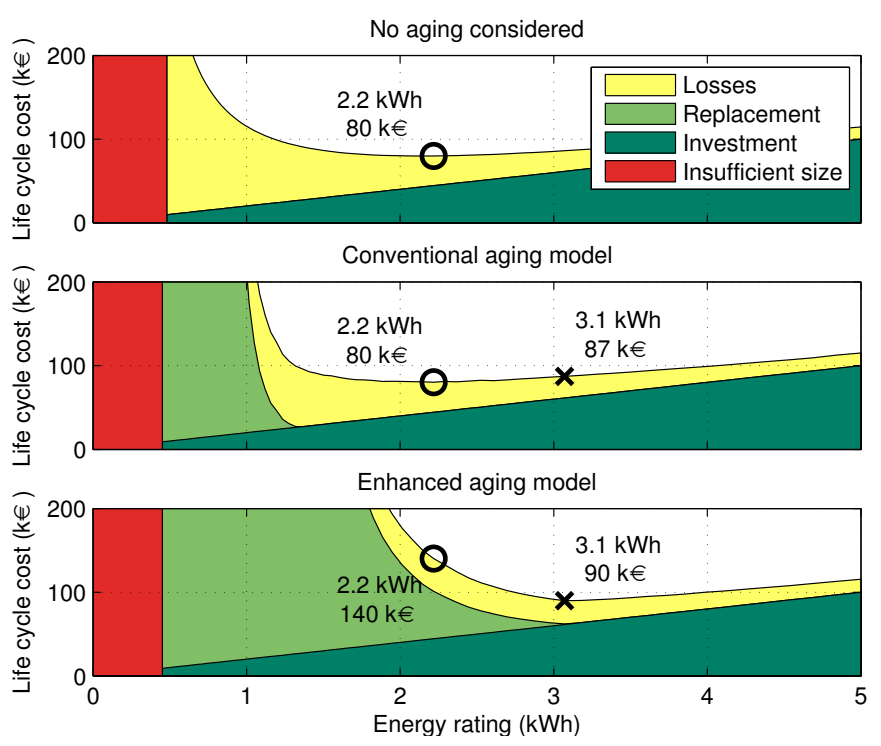

Fig. 10. Lifetime cost as a function of energy rating with three models: no consideration of aging, use of the conventional calendar model, and use of our enhanced model that takes current into account. The economic optimum with a conventional aging model is marked by a circle and the optimum obtained with the enhanced model is marked by a cross.

The minimum sizing to satisfy the flicker constraint depends on the sea-state, yet in all proposed sizing configurations, the energy amount is quite sufficient.

Let's note the importance of the aging model in the sizing process: without the enhanced model, the choice involves, above all else, a tradeoff between losses and investment; on the other hand, with the enhanced model, the choice becomes a tradeoff between investment and replacement. Furthermore, the optimum with the enhanced model corresponds to a sizing whose lifetime equals the useful life (13 years here): $N_{\text {replace }}$ is canceled out exactly with the optimum.

The robustness of the third optimum with the model is much higher than for the other two. Yet many uncertainties still remain: the aging model (naturally) with its set of input parameters, e.g. ambient temperature, in addition to the behavior of balancing circuits [18], component variability, maximum voltage or even thermal exchanges into the ESS [19]. Clearly, the larger the ESS, the more robust the life cycle cost.

\section{CONClusion}

The enhanced aging model presented in this paper has been built on the basis of several experiments conducted by the manufacturer or other laboratories. This model is able to explain cycling test results by taking into account the dependence of current on aging speed, in addition to the classical self-heating behavior.

This model was then applied to size an energy storage system for a Direct Wave Energy Converter. To satisfy the flicker constraint, it proved essential to smooth the power production, which led to the possibility of grid compliance. A simple energy management law was adopted in order to filter the power while ensuring a limited voltage range. In this case, the number of cycles turned out to be very high. This study has been compared with other hypotheses regarding aging. Results have demonstrated the advantages of an enhanced model for such a study, especially in the case of high power fluctuations and reliability requirements, which would be typical for DWEC.

The purpose of sizing is to minimize life cycle costs. A proposed formulation of this cost takes into account investment, replacement and losses. The final life cycle cost of around $90 \mathrm{k} €$ seems to be admissible, representing an impact on energy costs of $4 €$ per MWh.

To further decrease this cost, several solutions can be studied: switching technologies, a greater use of supercapacitors (even if the capacity drop exceeds $20 \%$ ), or improved energy management [20].

Let's point out however that the optimum is not always robust. This problem includes many sources of uncertainty, and a decision must be made (in terms of sizing selection): decision theory provides the typical tool to help quantify the robustness of a decision and the acceptable level of risk [21].

This study is only part of the design of a complete electric conversion chain that takes lifetime into account [22][23]. In the case of DWEC, other more efficient control strategies are available [24], though these would also be more stringent in terms of power fluctuation and hence in terms of flicker and fatigue cycling in supercapacitors. The influence of such control strategies for recovery modes should be considered in future research on this topic. 


\section{ACKNOWLEDGMENTS}

This work has been supported by the French National Research Agency (ANR) within the project QUALIPHE (power quality and grid integration of direct wave energy converters), which is part of the PROGELEC program.

\section{NOMENCLATURE}

$C \quad$ Capacity of the supercapacitor [F]

$C_{0} \quad$ Initial value of $C[\mathrm{~F}]$

$C_{E S S} \quad$ Capacity of the supercapacitor [F]

$C_{E S S 0} \quad$ Initial value of $C_{E S S}[\mathrm{~F}]$

$C_{\text {life }} \quad$ Life cost [€]

ESR Equivalent Series Resistance of the supercapacitor $[\Omega]$

$E S R_{0} \quad$ Initial value of $E S R[\Omega]$

$E S R_{E S S}$ Equivalent Series Resistance of the Energy Storage System $[\Omega]$

$\begin{array}{ll}E S R_{E S S 0} & \text { Initial value of } E S R_{E S S}[\Omega] \\ E_{S t o} & \text { Energy stored in the Energy Storage Sys- }\end{array}$ tem $[\mathrm{J}]$

$H_{s} \quad$ Significant height of a sea-state $(2.5 \mathrm{~m}$ here) $[\mathrm{m}]$

I $\quad$ Current flowing through the cell [A]

$I_{E S S} \quad$ Current flowing through the Energy Storage System [A]

$\tilde{I}_{R M S} \quad$ Estimation of the root mean square current flowing through the cell [A]

$K \quad$ Constant parameter for the aging law [-]

$k_{a c c}^{(i)} \quad$ Acceleration factor between calendar aging model computation and test results $[-]$

$k_{R M S} \quad$ Constant parameter for the aging law [s. $\mathrm{V}^{-1}$ ]

$N_{\text {Cells }} \quad$ Equivalent number of BCAP3000 in the Energy Storage System [-]

$N_{\text {Replace }} \quad$ Number of Energy Storage System replacements during the useful life of the entire system [-]

$P_{l t} \quad$ Long-term flicker severity [-]

$P_{\text {Grid }} \quad$ Grid power (after smoothing) [W]

$P_{\text {Loss }} \quad$ Power losses in the Energy Storage System [W]

$P_{\text {Prod }} \quad$ Production power (before smoothing) [W]

$P_{\text {Sto }} \quad$ Stored power in the Energy Storage System [W]

$R_{\text {thca }} \quad$ Thermal resistance between the case and the ambient temperature [K.W ${ }^{-1}$ ]

SoA State-of-Aging: equal to 0 at the beginning and reaches 1 when $C=0.8 C_{0}$ or $E S R=2 E S R_{0}[-]$
$T_{\text {life }}\left(V, \theta_{c}\right)$ Lifetime with a terminal voltage of the capacity $V$ and case temperature $\theta_{c}[\mathrm{~h}]$

$$
T_{\text {life }}^{\text {ref }}
$$

$T_{\text {life }}^{(i)}$
$\tilde{T}_{\text {life }}^{(i)}$

$T_{p}$

$V$

$V^{\text {ref }}$

$V_{0}$

$V_{E S S}$

$V_{\text {Rated }}$

$\triangle S o A$

$\theta_{0}$

$\theta_{a}$

$\theta_{c}$

$\theta_{c}^{r e f}$

$\tau_{\text {filter }}$

$\tau_{\text {Sto }}$ Reference lifetime for a reference case condition $T_{\text {life }}^{r e f}=T_{\text {life }}\left(V^{\text {ref }}, \theta_{c}^{\text {ref }}\right)$, a constant parameter for the aging model [h]

Lifetime measured for experiment $\mathrm{i}[\mathrm{h}]$

Estimation thanks to an aging model of the lifetime for experiment $\mathrm{i}[\mathrm{h}]$ Peak period of a sea-state ( $8 \mathrm{~s}$ here) [s] Capacitive voltage of the cell [V] Reference value for $V$ (2.7 V here) [V] Constant parameter for the aging law [V] Capacitive voltage of the cell [V]

Rated capacitive voltage of the cell (2.7 V here) [V]

Aging resolution for the lifetime estimations (1\% here) [-]

Constant parameter for the aging law $[\mathrm{K}]$ Ambient temperature $\left[{ }^{\circ} \mathrm{C}\right]$

Case temperature of the cell $\left[{ }^{\circ} \mathrm{C}\right]$

Reference value for $\theta_{c}\left(65^{\circ} \mathrm{C}\right)\left[{ }^{\circ} \mathrm{C}\right]$

Time constant of the filter used to compute $\tilde{I}_{R M S}$ (in seconds)

Time constant of the smoothing filter applied by the Energy Storage System with its energy policy (in seconds)

\section{REFERENCES}

[1] B. Vulturescu, R. Trigui, R. Lallemand, and G. Coquery, "Implementation and test of a hybrid storage system on an electric urban bus," Transportation Research Part C: Emerging Technologies, vol. 30, pp. 55-66, May 2013.

[2] Z. Zhou, F. Scuiller, J. F. Charpentier, M. Benbouzid, and T. Tang, "Grid-connected marine current generation system power smoothing control using supercapacitors," in IECON 2012 - 38th Annual Conference on IEEE Industrial Electronics Society. IEEE, Oct. 2012, pp. 4035-4040.

[3] Maxwell Technologies, "Datasheet K2 Series Ultracapacitors," pp. 1-4, 2007.

[4] H. Gualous, R. Gallay, G. Alcicek, B. Tala-Ighil, A. Oukaour, B. Boudart, and P. Makany, "Supercapacitor ageing at constant temperature and constant voltage and thermal shock," Microelectronics Reliability, vol. 50, no. 9-11, pp. 1783-1788, Sep. 2010.

[5] O. Briat, J.-m. Vinassa, N. Bertrand, E. H. El Brouji, J.-y. Deletage, and E. Woirgard, "Contribution of calendar ageing modes in the performances degradation of supercapacitors during power cycling," Microelectronics Reliability, vol. 50, no. 9-11, pp. 1796-1803, Sep. 2010.

[6] O. Bohlen, J. Kowal, and D. U. Sauer, "Ageing behaviour of electrochemical double layer capacitors Part I. Experimental study and ageing model," Journal of Power Sources, vol. 172, no. 1, pp. 468-475, Oct. 2007.

[7] R. Kötz, P. Ruch, and D. Cericola, "Aging and failure mode of electrochemical double layer capacitors during accelerated 
constant load tests," Journal of Power Sources, vol. 195, no. 3, pp. 923-928, Feb. 2010.

[8] P. Kreczanik, "Etude de la fiabilité et du vieillissement d'un système de stockage par supercondensateurs pour l'alimentation partielle et ponctuelle d'un trolleybus grâce à la récupération de l'énergie de freinage. Approche du composant au système de stockage (french)," Ph.D. dissertation, Université Claude Bernard Lyon 1, 2011.

[9] P. Kreczanik, P. Venet, A. Hijazi, and G. Clerc, "Study of Supercapacitor Ageing and Lifetime Estimation According to Voltage, Temperature and RMS Current," Industrial Electronics, IEEE Transactions on, vol. 61, no. 9, pp. 4895-4902, 2014. [Online]. Available: http://ieeexplore.ieee.org/xpls/abs_all.jsp?arnumber=6678762

[10] E. L. Hassane, E. Brouji, J.-M. Vinassa, O. Briat, N. Bertrand, J.-Y. Deletage, and E. Woirgard, "Ageing assessment of supercapacitors during calendar life and power cycling tests," in Energy Conversion Congress and Exposition, 2009. ECCE 2009. IEEE, 2009, pp. 1791-1798.

[11] A. Blavette, D. L. O'Sullivan, T. W. Lewis, and M. G. Egan, "Dimensioning the equipment of a wave farm: Energy storage and cables," in Ecological Vehicles and Renewable Energies (EVER), Eighth International Conference and Exhibition on, Mar. 2013, pp. 1-9.

[12] A. Babarit, M. Guglielmi, and A. H. Clément, "Declutching control of a wave energy converter," Ocean Engineering, vol. 36, no. 1213, pp. 1015-1024, Sep. 2009. [Online]. Available: http://linkinghub.elsevier.com/retrieve/pii/S0029801809001115

[13] J. Aubry, P. Bydlowski, B. Multon, H. Ben Ahmed, and B. Borgarino, "Energy Storage System Sizing for Smoothing Power Generation of Direct Wave Energy Converters," in 3rd International Conference on Ocean Energy, Bilbao, Oct. 2010, pp. 1-7. [Online]. Available: http://hal.archives-ouvertes.fr/hal00526435/

[14] E. H. El Brouji, "Prise en compte du vieillissement dans la modélisation des supercondensateurs (in french)," Ph.D. dissertation, Université Bordeaux I, 2009.

[15] R. German, P. Venet, A. Sari, O. Briat, and J.-M. Vinassa, "Improved Supercapacitor Floating Ageing Interpretation Through Multi-pore Impedance Model Parameters Evolution," Power Electronics, IEEE Transactions on, vol. 29, no. 7, pp. 3669,3678, 2014.

[16] Maxwell Technologies, "Application note: Maxwell Technologies BOOSTCAP Energy Storage Modules Life Duration Estimation," pp. 4-5, 2007.

[17] International Electrotechnical Commission, "IEC 61400-21 Wind turbine generator systems Measurement and assessment of power quality characteristics of grid connected wind turbines," 2001.

[18] P. Kreczanik, T. Kovaltchouk, A. Hijazi, P. Venet, and G. Clerc, "Consideration of the ageing in the control of the balancing circuit of supercapacitor," in Super Capacitors \& Applications, Proc. of the 4th European Symposium on - ESSCAP 2010, Bordeaux, 2010.

[19] A. Hijazi, P. Kreczanik, E. Bideaux, P. Venet, G. Clerc, and M. Di Loreto, "Thermal Network Model of Supercapacitors Stack," Industrial Electronics, IEEE Transactions on, vol. 59, no. 2, pp. 979-987, 2012.

[20] P. Haessig, T. Kovaltchouk, B. Multon, H. Ben Ahmed, and S. Lascaud, "Computing an Optimal Control Policy for an Energy Storage," in EuroScyPy, Brussels, 2013, pp. 1-8.
[Online]. Available: http://xn-ole-9la.net/publications/Haessig 2013 ESPy - Optimal control Python.pdf

[21] R. Chedid, H. Akiki, and S. Rahman, "A decision support technique for the design of hybrid solar-wind power systems," Energy Conversion, IEEE Transactions on, vol. 13, no. 1, pp. pp.76,83, 1998.

[22] J. Aubry, H. Ben Ahmed, and B. Multon, "Sizing Optimization Methodology of a Surface Permanent Magnet MachineConverter System over a Torque-Speed Operating Profile : Application to a Wave Energy Converter," Industrial Electronics, IEEE Transactions on, vol. 59, no. 5, pp. 2116,2125, 2012.

[23] T. Kovaltchouk, J. Aubry, B. Multon, and H. Ben Ahmed, "Influence of IGBT current rating on the thermal cycling lifetime of a power electronic active rectifier in a direct wave energy converter," in Power Electronics and Applications (EPE 2013), Proceedings of the 2013-15th European Conference on, no. September. Lille: Ieee, Sep. 2013, pp. 1-10. [Online]. Available: http://hal.archives-ouvertes.fr/hal-00864070

[24] T. Kovaltchouk, B. Multon, H. Ben Ahmed, F. Rongère, A. Glumineau, and J. Aubry, "Influence of control strategy on the global efficiency of a Direct Wave Energy Converter with electric Power Take-Off," in Ecological Vehicles and Renewable Energies (EVER), 2013 Eighth International Conference and Exhibition on, 2013, pp. 1,10. [Online]. Available: http://hal.archives-ouvertes.fr/hal-00831687 